\title{
Substantiation of the algorithm of information technology for energy monitoring of tractor engines
}

\author{
Viktor V. Alt ${ }^{1}$, Oleg F. Savchenko ${ }^{1}$, Oleg V. Elkin ${ }^{1}$ and Ivan P. Dobrolyubov ${ }^{1}$ \\ ${ }^{1}$ Siberian Institute of Physics and Technology of Agrarian Problems, Siberian Federal Scientific Center of \\ Agrobiotechnologies of the Russian Academy of Sciences, Krasnoobsk, Novosibirsk Region, Russia
}

\begin{abstract}
It is shown that it is necessary to control the energy indicators of automotive engines to ensure the operational efficiency of agricultural machinery in operational conditions. An algorithm for monitoring the energy indicators of the machine and tractor fleet of an agricultural enterprise is proposed, reflecting the main stages of obtaining, processing, storing and applying diagnostic information. Due to the timely assessment of the state of the equipment and the performance of the necessary maintenance, the efficiency of its work is increased.
\end{abstract}

\section{Keywords}

Machine and tractor fleet, internal combustion engine, energy supply of agricultural production, operational parameters, power, dynamic model, information modeling, databases.

\section{Problem statement}

One of the important indicators of the level of development of agricultural production is the energy supply of its sown areas (the total power of combine harvesters, tractors and other equipment $(\mathrm{kW})$ per $1 \mathrm{ha})$. Despite the insufficient level of this indicator in Russia for the timely and high-quality performance of agricultural work, there is a tendency to decrease it over the past 20 years. Every year, the tractor fleet is reduced by an average of $7 \%$, the fleet of combine harvesters - by $8 \%$; a further annual reduction of the park by $10-12 \%$ is predicted, which also determines a decrease in the energy supply of agricultural field work. For example, in Novosibirsk Region, there has been a decrease in the total engine power of tractors, combines and self-propelled machines over the past five years by $20.6 \%$ [1].

This negative trend is significantly complemented by the inevitable loss (decrease) of the capacity of mobile agricultural machinery when directly performing field agricultural work. This is due to the deterioration of the technical condition of the internal combustion engine (ICE), the main energy means of the machine and tractor fleet (MTP) of the agricultural enterprise due to wear of parts, violations of adjustments and settings of mechanisms and systems, aggravated by the aging of the equipment in operation, the need to use equipment with an average service life of more than 10 years. The lack of the control over the parameters of the technical condition of the MTP internal combustion engine (power, fuel consumption-without special means) when

SDM-2021: All-Russian conference, August 24-27, 2021, Novosibirsk, Russia

$\bigoplus$ sof-oleg46@yandex.ru (O.F. Savchenko)

(c) (1) ๑ 2021 Copyright for this paper by its authors. Use permitted under Creative Commons License Attribution 4.0 International (CC BY 4.0).

CEUR Workshop Proceedings (CEUR-WS.org) 
performing agricultural work leads to the use of tractors with excessive fuel consumption by $10-15 \%$ due to loss of traction properties.

The practical reduction in the volume of the machine and tractor fleet in agricultural production, the existing unavoidable power losses of the MTP internal combustion engine during the performance of work justify the need for accelerated development of research aimed at the development and practical implementation of high-performance methods and systems for operational control of the technical condition of the internal combustion engine. Among them, an important place is occupied by methods for evaluating energy parameters, automating the determination of the dynamics of changes in the power of the internal combustion engine in operational conditions.

The well-known method of energy assessment of agricultural machinery according to GOST 52777 involves the use of fuel flow meters and the use of regulatory characteristics of the internal combustion engine, obtained, as a rule, during bench tests of engines, which excludes the use of the method in operational conditions.

Therefore, for the operational control of energy indicators, the most promising, in our opinion, is the use of a well-known dynamic method for diagnosing tractor engines, using measurement and analysis of angular velocity and acceleration of the crankshaft in dynamic modes of internal combustion engine operation [2]. This method is characterized by large amounts of information obtained from the internal combustion engine and subject to in-depth analytical processing for calculating the energy parameters of the internal combustion engine. To do this, it is necessary to attract high-speed diagnostic technical means, advanced digital technologies for data transmission and processing, which, unlike analog equipment, allow combining the entire technological process of monitoring agricultural machinery into a single whole. The practical application of this information approach in the engineering and technical sphere of the agro-industrial complex is facilitated by successfully developing statistical methods of signal analysis, information computer modeling of technological processes, telemetry and monitoring of agricultural machinery $[3,4,5,6]$.

The problematic situation is characterized by the fact that the existing methods of organization and means of maintenance and repair do not fully meet the requirements necessary for the effective use of the machine and tractor fleet. Therefore, the development of new methods and tools for operational maintenance of equipment based on automation of monitoring of its energy indicators, especially in the operational (field) conditions of a particular farm, is a necessary task.

The purpose of the study is to develop an algorithm for automating the monitoring of energy indicators of equipment using a dynamic model of internal combustion engines and information technologies for data collection and processing.

\section{Research methods}

Automated energy monitoring uses signals of physical processes that characterize the operation of the engine, coming from standard and (or) specially installed sensors (for example, sensors of the angular position of the crankshaft). In the presence of an electronic control system of the internal combustion engine, signals determined by the standard communication protocol are 
used. After the measurement and pre-processing of the signals from the sensors, the information is processed. To determine the power of the internal combustion engine, a computer dynamic model of the internal combustion engine is used, developed taking into account the longterm experience of developers, taking into account the non-linearity and non-stationarity of individual links, the influence of changes in many important parameters of individual units and systems and the manifestation of significant non-linearities and other deviations on the output processes of the engine in the function of time, angular displacement, speed and load modes [7]. In this case, the time, frequency and statistical characteristics of the processes, their partial and integral indicators are calculated the angular acceleration of the crankshaft is calculated (the most information-intensive for calculating energy parameters).

An important scientific and methodological aspect in the development of the algorithm is the need to analyze measurement information, evaluate methodological errors. When diagnosing the state of the internal combustion engine, signals of physical processes are used that characterize the operation of the engine. After the measurement and pre-processing of the signals from the sensors, the information is processed. At the same time, errors accumulate in the measuring channel from the sensor to the microprocessor device. The randomness of the fuel supply and combustion processes from cycle to cycle, as well as the friction processes in the ice interfaces, cause random deviations of the angular velocity and acceleration of the crankshaft $\omega(t)$ and $\varepsilon(t)$ from their average values. This leads to the need to consider the measured processes as an additive combination of a useful informative process and interference. To determine the parameters, it is advisable to use known probabilistic methods of signal analysis, statistical methods of optimal signal processing against the background of interference. This allowed us to justify the optimal method for detecting the structural parameters of the internal combustion engine hidden in the high level of other components of working processes and measuring the informative parameters of signals reflecting these parameters by a measuring expert system [8].

The methodological feature of the research is the need to take into account the fact that modern automotive engines are equipped with an electronic control system that provides the necessary algorithm for controlling the engine operating modes based on the characteristics of the measured values of the engine parameters. Hence, the principle of creating diagnostic systems using the tractor's on-board network is obvious - it is diagnosed by various analytical methods according to the measured processes not only from special installed sensors of the physical processes of the internal combustion engine (for example, sensors of the angular position of the crankshaft), but also using signals determined by the standard communication protocol from sensors of the electronic control system. Here, the proposed method for determining the power of an internal combustion engine based on the study of the dynamics of the internal combustion engine (the transient process of the angular velocity of the crankshaft) during diagnostic tests is of practical value. At the same time, both time interval flows from the crankshaft speed sensors and request-receive packets of the speed parameter via the CAN bus from the engine electronic unit via the OBD-II diagnostic connector are measured using the developed diagnostic system based on the NI sbRIO-9694 device [9].

Much attention is paid to the creation of information support for the entire cycle of the technological process, providing data registration, processing and visualization of results based on a convenient user interface. The basis can be the created special software of the automated digital technology of internal combustion engine energy assessment using a convenient user 
interface, providing the user with the opportunity, among others, to directly control the process of submitting test effects, registering and visualizing data [10].

The practical implementation of the algorithm, including complex algorithms for modeling ICE transients, calculating speed characteristics and energy parameters, receiving, transmitting and visualizing data is carried out using computer information and communication digital technologies.

\section{Research results and recommendations}

The main elements of the algorithm are the measurement of the speed of rotation of the crankshaft during dynamic test actions on the internal combustion engine; synchronization of measurements with monitoring and ensuring the necessary number of full-fledged single test actions in the test cycle. According to the measurement data, the speed and regulatory dynamic characteristics of the internal combustion engine in terms of power and torque are constructed, which are necessary for calculating the complex of diagnostic energy characteristics.

The practical implementation of the algorithm, including complex algorithms for modeling ICE transients, calculating speed characteristics and energy parameters, receiving, transmitting and visualizing data is carried out using computer information and communication digital technologies.

The algorithm also provides information support for the technological process of evaluating the power of the internal combustion engine: input and correction of the initial data for the machine and tractor fleet of the agricultural enterprise (the database of the initial parameters of the MTP) is provided; measurement, registration of data of the physical processes of the internal combustion engine and their processing (calculation of energy parameters) using the test mode of the internal combustion engine is monitored and their comparison with the passport data for each unit of equipment and for the entire machine and tractor fleet is checked.

The database of the initial parameters of the MTP includes the following set of parameters and data for each brand of equipment:

- effective engine power $\mathrm{Ne}, \mathrm{kW}$;

- torque on the motor shaft $\mathrm{Me}, \mathrm{nm}$;

- hourly fuel consumption $\mathrm{Gt}, \mathrm{kg} / \mathrm{h}$;

- ge specific fuel consumption, $\mathrm{g} / \mathrm{kWh}$;

- the speed of rotation of the crankshaft $\mathrm{n}, \mathrm{Hz}$;

- operating time (tractors with units for operations), Ha;

- duration (days) and types of repairs by brands of all units of equipment;

- the date of commissioning according to the brands of all units of equipment.

In case of deviation from the established standards, a recommendation is given for further maintenance or repair. The current data of monitoring the energy indicators of the fleet of cars are entered into a special database of monitoring results for analysis and making operational and other management decisions on reliable energy supply of field work of the agricultural enterprise. Figure 1 shows the scheme of the algorithm for automating the monitoring of energy indicators of the machine and tractor fleet of a separate agricultural enterprise. 


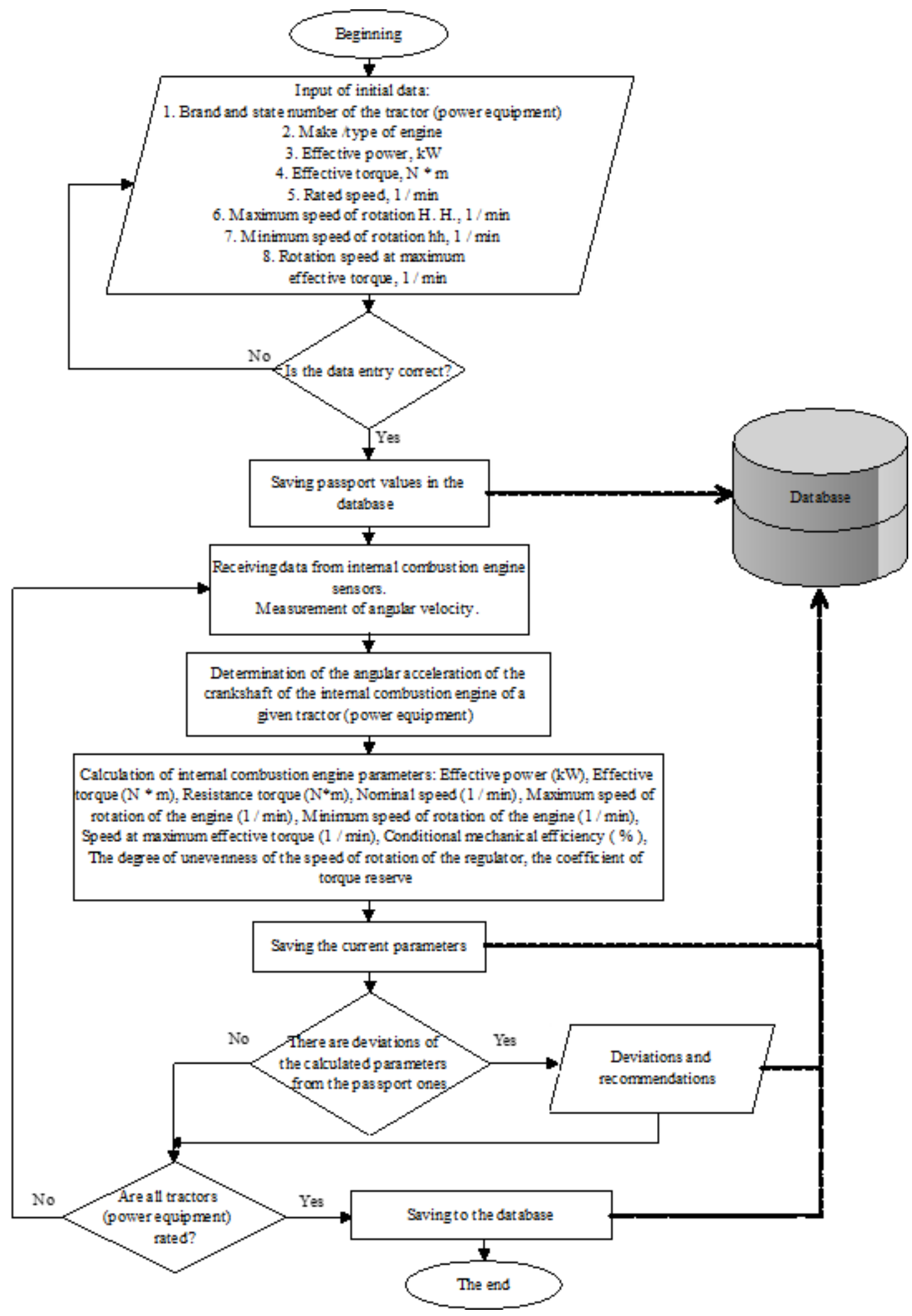

Figure 1: Diagram of the algorithm for monitoring energy indicators. 
To determine the speed characteristic, according to which the power of the internal combustion engine and its other parameters are calculated, signals are used from a specially installed crankshaft position sensor (DPKV) in the clutch housing opposite the gear ring of the flywheel or from a standard internal combustion engine sensor via the diagnostic connector (OBD-II). The information database contains passport information on the internal combustion engines of the agricultural enterprise's MTP park, their nominal values in the corresponding modes, permissible deviations and permissible deviation time. Along with the manual input mode, there is also a training mode-instrumental data entry into the database under the appropriate modes (known, standard) of the internal combustion engine operation.

An experimental test of the digital technology was carried out on the basis of the developed algorithm for evaluating the power of tractor internal combustion engines in the conditions of an agricultural enterprise during field work [11,12]. In the monitoring mode, the current value of the analyzed parameters was periodically monitored. According to the results of the tests of the internal combustion engine, the results were analyzed and the current values were compared with the passport parameters of the internal combustion engine, the dynamics of changes in operational parameters were evaluated, deviations of the values of effective power and fuel consumption were determined. Based on the results of the analysis, recommendations were promptly issued for making management decisions on the further operation of each piece of equipment - continuing work or the need for repair and adjustment work. All the data of the current monitoring are entered into the MTP database, which is used for complex analysis, creation of a working archive of the economy and scientifically-based planning of the energy supply of field work.

For further development of the work, it is necessary to improve the sensors of the physical processes of the internal combustion engine, the construction of built-in remote diagnostics tools. It is very promising to obtain information about the dynamics of the internal combustion engine by forming mathematical information models that use the laws of its functioning during direct field work, which are characterized by unsteady operating modes with a wide change in the load range and the speed of rotation of the crankshaft. This will make it possible to further eliminate the need for special labor-intensive acceleration-run-out test cycles and create conditions for the development of algorithms for automated (automatic) autonomous control of machine-tractor units.

\section{Conclusions}

The expediency of using the energy monitoring of the agricultural enterprise's MTP under operating conditions is shown, the structural scheme of the information technology algorithm is justified, which allows, on the basis of operational control of the energy parameters of tractor engines, to carry out timely necessary repair and maintenance measures to reduce power losses.

The use of digital technology built using the algorithm made it possible to determine the dynamics of changes in the power of the ICE of the MTP fleet in production conditions, to assess the possibility of continuing the operation of the equipment or to identify the need for repair and adjustment work and to take appropriate operational control decisions.

The proposed algorithm can be used as a scientific and methodological basis for the formation 
of robotic technologies for controlling machine-tractor units based on mathematical models reflecting the laws of their functioning.

\section{References}

[1] Stadnik A.T., Kabakov V.M., Kabakova O.G. Technical equipment of agricultural production in the region and ways of its improvement // Vestnik of Novosibirsk State Agrarian University. 2018. No. 1(46). P. 166-173.

[2] Dobrolyubov I.P., Livshits V.M. Dynamic method of diagnostics of automotive engines. Principles of constructing diagnostic models of transients: A method of recommendation // VASHNIL, Sib. Otd-nie, SibIME. Novosibirsk, 1981. 88 p.

[3] Degtyarev D.A. Features of integration of information technologies and machine systems for the purpose of complex mechanization of crop production // Bulletin of the Altai State Agrarian University. 2020. No. 9(191). P. 115-123.

[4] Didmanidze O.N, Dorokhov A.S., Kataev Yu.V. Trends in the development of digital technologies for diagnosing the technical condition of tractors // Machinery and Equipment for the Village. 2020. No. 11(281). P. 39-43.

[5] Golubev I.G., Mishurov N.P., Goltyapin V.Ya., Apatenko A.S. Sevryugina N.S. Telemetry and monitoring systems for agricultural machinery: Analytical overview. Moscow: Rosinformagrotekh, 2020. $76 \mathrm{p}$.

[6] Alt V.V. Dobrolyubov I.P., Savchenko O.F., Klimenko D.N., Elkin O.V. Methodological basis for measuring expert systems automation of motor and tractor engines // Siberian Herald of Agricultural Science. 2020. Vol. 50. No. 4. P. 80-92. DOI:10.26898/0370-8799-2020-4-10.

[7] Dobrolyubov I.P., Savchenko O.F., Alt V.V., Olshevskiy S.N. Development of a modifiable computer model for internal combustion engine // Computational Technologies. 2013. Vol. 18. No. 6. P. 54-61. (In Russ.)

[8] Dobrolyubov I.P., Savchenko O.F., Alt V.V., Olshevsky S.N., Klimenko D.N. Modeling the process of optimal determination for the parameters of the conditions of internal combustion engine by measuring expert system // Computational Technologies. 2015. Vol. 20. No. 6. P. 22-35. (In Russ.)

[9] Savchenko O.F., Dobrolyubov I.P. Modeling the process for identification of tractor engine states // Problems of Computational and Applied Mathematics. 2016. No. 4(6). P. 4-12. (In Russ.).

[10] Alt V.V., Olshevsky S.N., Klimenko D.N., Borisov A.A., Orekhov A.K. Determination of the power of automotive engines by the parameters of the on-board diagnostics system // Works of GOSNITI. 2015. Vol. 119. P. 151-156.

[11] Alt V.V., Savchenko O.F., Elkin O.V. Digital technology for assessing the capacity of the tractor fleet of an agricultural enterprise // Agricultural Machinery and Technologies. 2019. Vol. 13. No. 4. P. 25-31. DOI:10/22314/2073-7599-2019-13-4-25-31.

[12] Savchenko O.F., Elkin O.V., Sapronov V.N. Evaluation of the power of tractor engines in production conditions using the device "MOTOR-TESTER SIBFTI" // Mat. Intern. Sci. and Tech. Conf. "Scientific and Technical Support of the Agroindustrial Complex of Siberia". Novosibirsk: SibIME SFNCA RAS, 2017. Vol. 1. P. 390-394. 